\title{
There is little evidence that combined vaccination against measles, mumps, and rubella is associated with autism
}

Madsen K, Hviid A, Vestergaard M et al. A population-based study if measles, mumps, and rubella vaccination and autism. N Eng J Med 2002 Nov;347:1477-82.

QUESTION: Is the combined measles, mumps and rubella (MMR) vaccination associated with autism?

\section{Design and setting}

Retrospective population study of all children born in Denmark between January 1991 and December 1998.

\section{Participants}

537,303 children were born during the study period; $49 \%$ girls. $82 \%$ received the MMR vaccine.

\section{Assessment of risk factors}

The Danish Civil Registration System assigns a unique identification number to every live birth and new resident in Denmark. MMR vaccination status was obtained from the Danish National Board of Health. Information about potential confounders was obtained from the Danish Medical Birth Registry, the National Hospital Registry and Statistics Denmark.

\section{Main outcome measures}

Autism status was obtained from the Danish Psychiatric Central Register, containing all diagnoses from psychiatric hospitals and outpatient clinics in Denmark.

\section{Main results}

Children receiving the MMR vaccination were no more likely to develop autism than non-vaccinated children (table). There was no clustering of autism diagnoses according to time after vaccination, age of the child at vaccination or date of vaccination.

Source of funding

Danish National

Research Foundation

National Vaccine

Programme Office;

National

Immunization

Program, Centers for

Disease Control and

Prevention; National

Alliance for Autism

Research.

For correspondence: KM Madsen, Danish Epidemiology Science Centre, Department of

Epidemiology and

Social Medicine,

Aarhus, Denmark

kmm@dadlnet.dk

\section{Conclusions}

The authors found no evidence that the combined measles, mumps and rubella vaccination is associated with the development of autism.
Relationship between MMR vaccination and risk of autism

\section{COMMENTARY}

This is the most direct evaluation of whether MMR causes autism published to date. Though all epidemiological studies conducted in recent years have found no association between the MMR vaccine and onset of autism, design limitations have left some doubt about this issue. ${ }^{1-5}$ This historical cohort included all Danish children born between 1991 and 1998 when prevalence rates for autism and autistic spectrum disorders were increasing. Because of the thoroughness of the Danish system of registration, ascertainment of vaccination status and health problems was remarkably accurate and complete. Since the cohort was composed of the entire population, both vaccinated and unvaccinated children had the same risk of autism prior to exposure to the vaccine. Nearly all children were accounted for at the end of the study period. Specialists using the same diagnostic classification system made the diagnosis of autism in a uniform manner.

This study suggests that there was no difference in the risk of autism in the vaccinated versus unvaccinated groups and that there was no clustering of cases at any time after immunization. The registry data did not include information about children with developmental regression. The issue of whether there is a subgroup of children vulnerable to the vaccination cannot be entirely laid to rest from this study. One would think that if such a group existed, relative risk would be greater than 1.0 for the vaccinated children. The opposite was true, though not to a significant degree.

Based on the size of this cohort and the lack of evidence of differential risk for autism, this study suggests that parents should continue vaccinating their children to avoid future outbreaks of measles and the risk of serious neurological sequelae.

Lee Tidmarsh, MDCM FRCPC McGill University

Montreal, Quebec, Canada

1 Fombonne E. The prevalence of autism. JAMA 2003; 289: $87-9$

2 Smeeth L, Hall AJ, Fombonne E et al. A case-control study of autism and mumps-measles-rubella vaccination using the general practice research database: design and methodology. BMC Public Health 2001; 1: 2.

3 Smeeth L, Hall AJ, Rodriques LC et al. Measles, mumps, and rubella vaccine and autism: ecological studies cannot answer main question. BMJ 2001; 323: 163.

4 Taylor B, Miller E, Farrington CP et al. Autism and measles, mumps, and rubella vaccine: no epidemiological evidence for a causal association. Lancet 1999; 353: 2026.

5 Fombonne E, Chakrabarti S. No evidence for a new variant of measles-mumps-rubella-induced autism. Pediatrics 2001; 108.

\begin{tabular}{|c|c|c|c|}
\hline & $\begin{array}{l}\text { MMR vaccinated children } \\
(n=440655)\end{array}$ & $\begin{array}{l}\text { No MMR vaccination } \\
(n=96648)\end{array}$ & $\begin{array}{c}\text { Adjusted relative risk from } \\
\text { MMR }(95 \% \mathrm{CI})\end{array}$ \\
\hline Number who developed autism & 263 & 53 & $0.92(0.68$ to 1.24$)$ \\
\hline $\begin{array}{l}\text { Number who developed } \\
\text { autism-spectrum disorder }\end{array}$ & 345 & 77 & $0.83(0.65$ to 1.07$)$ \\
\hline
\end{tabular}

